Кинденко Н. И.

\title{
ВЛИЯНИЕ ПАРАМЕТРОВ РЕЖИМА МАГНИТНОЙ ОБРАБОТКИ НА СТРУКТУРНЫЕ ИЗМЕНЕНИЯ В ИНСТРУМЕНТЕ ДЛЯ ОБСЕЧКИ
}

Проблема износостойкости и долговечности обсечных матриц для холодной и объёмной штамповки болтов и гаек имеет чрезвычайно большое значение. В настоящее время разработаны способы повышения стойкости инструмента, которые основаны на использовании сложных физических явлений как в процессе работы инструмента, так и при его изготовлении.

Улучшение качества инструментов можно достичь легированием материалов, а также с применением всех известных механизмов объемного упрочнения при термической обработке. Причины отказов инструментов чаще всего связаны не с их поломкой, а с утратой ими своей первоначальной поверхностной конфигурации в следствие износа, сколов, смятия, растрескивания, т. е. в связи с разрушением или деформации тонких поверхностных слоев металла [1].

Одним из основных направлений физической технологии является магнитная обработка материалов. В целом, результат магнитной обработки рассматривается как проявление эффектов последействия в материалах, находящихся на границах стабильности их свойств и подвергнутых воздействию внешнего силового поля [2].

При магнитном воздействии вещество изменяет свои физические и механические свойства.

Улучшение свойств у ферромагнитных деталей, прошедших магнитно-импульсную обработку (МИО), достигается за счет направленной ориентации свободных электронов вещества внешним полем, вследствие увеличивается тепло- и электропроводимость материала. Взаимодействие импульсного магнитного поля с деталью из токопроводящего материала происходит тем интенсивнее, чем выше структурная и энергетическая неоднородность вещества [3].

Поля локальных перенапряжений в быстрорежущих сталях появляются в результате магнитострикции. В этих условиях частицы карбидной фазы оказываются концентраторами напряжений, которые уменьшаются за счет дополнительных источников дислокаций.

В целом результат магнитной обработки рассматривается как проявление эффектов последействия в материалах, находящихся на границах стабильности их свойств и подвергнутых воздействию внешнего силового поля.

Вместе с тем пока еще нет единого, всесторонне подтвержденного взгляда на причины, вызывающие изменение эксплуатационных свойств инструмента в результате воздействия импульсного магнитного поля.

Цель работы - на базе известных теоретических представлений исследовать влияние параметров режимов импульсной магнитной обработки на стойкость обсечных матриц из быстрорежущих сталей.

Энергетическое состояние ферромагнетика определяется энергетическим и квантовым взаимодействием магнитных моментов всех внешних электронов атомов вещества, образующих конкретную деталь.

Для конкретного атома сплава его энергетическое состояние $(\Phi)$ с учетом его возбуждения внешним магнитным полем можно определить по следующей зависимости:

$$
\Phi=\Phi(x, y, z, t) \times S\left({ }_{L}\right) \times P S,
$$

где $\Phi(x, y, z, t)$ - энергетическое состояние материала массой $m$ при объеме $V$;

$S(L)$ - неравновесное состояние атомов вещества, способных изменять его под действием внешнего магнитного поля средней напряженности;

$P s$ - коэффициент, характеризующий магнитную энергию этих атомов. 
При изготовлении реальных деталей в материале неравномерно концентрируется некоторое количество избыточной энергии $(F)$, с увеличением которой возрастает вероятность разрушения детали $(P)$.

Для повышения надежности работы механизма необходимо величину максимальной вероятности разрушения детали снизить примерно в 4 раза. Это возможно за счет уменьшения избыточной энергии материала внешними физико-технологическими методами.

Из рис. 1 следует, что для каждого материала существует оптимальное значение внешнего импульсного магнитного поля $H_{\text {опm }}$, при котором концентрация напряжений в материале, а следовательно, и избыточная энергия предельно уменьшается (F $\rightarrow$ Fmin), вследствие чего повышается надежность детали.

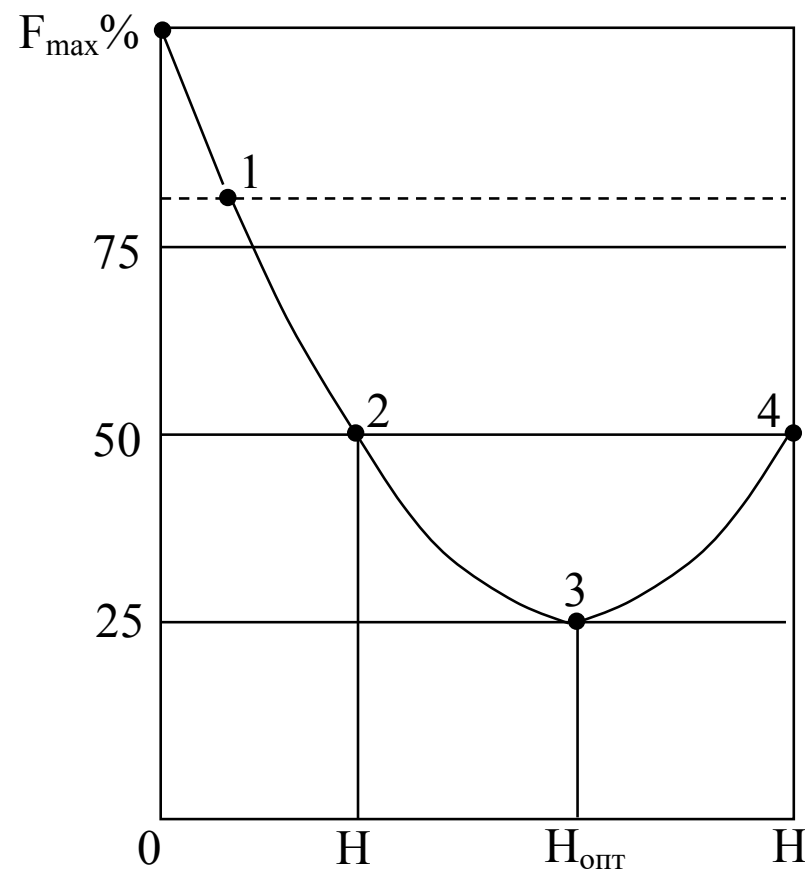

a

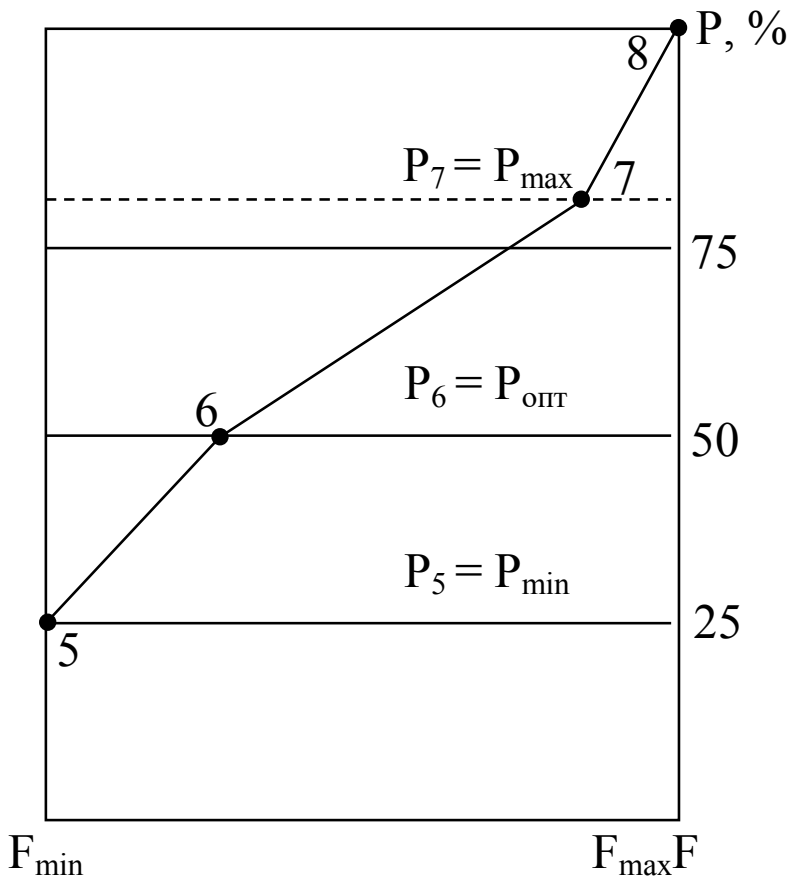

6

Рис. 1. Изменение избыточной энергии $F$ в образце из ферромагнитного сплава в зависимости от напряженности поля $H$ при МИО (а) и влияние избыточной энергии $F$ на вероятность разрушения детали $P($ б)

Для уменьшения значения избыточной энергии в материале конкретного инструмента необходимо затратить некоторое количество электромагнитной энергии $\left(W_{o}\right)$, которая может быть определена из уравнения:

$$
W_{o}=K_{1} \cdot K_{2} \iint_{m} \int_{\Phi} m d m \cdot V_{d} \cdot V_{m} \cdot \Phi^{n} \cdot d \Phi,
$$

где

K1 - коэффициент, учитывающий влияние концентраций поверхностных и внутренних напряжений на стойкость инструмента (связан с конструированием и технологией изготовления детали (для стальных деталей $\left.\mathrm{K}_{1}=1,5 \ldots 2,5\right)$ );

К2 - коэффициент, учитывающий потери энергии при МИО детали;

$\Phi$ - функция, отражающая физико-механические свойства материала;

$n$ - показатель, учитывающий надежность детали (для стальных деталей, работающих при статических нагрузках $n=2$ ).

Энергия магнитного поля, развиваемая соленоидами магнитно-импульсных установок, определяется по формуле: 


$$
W=K 2 \times(B \times H) \times V
$$

где

$B$ - магнитная индукция в соленоиде, Тл;

$H$ - напряженность магнитного поля, А/м;

$V$ - объем пространства, где концентрируется магнитное поле, м $^{3}$.

При МИО за время импульса в соленоиде установки выделяется энергия магнитного поля, которая распределяется в основном следующим образом:

$$
W_{o}=K_{H n} \times(W 1+W 2)
$$

где

$K_{н n}-$ коэффициент неучтенных потерь энергии, зависящий от взаимоиндукции поля детали с полем соленоида;

W1 - энергия, расходуемая на намагничивание детали, Дж;

W2 - энергия, расходуемая на локальный нагрев детали, Дж.

Энергия, расходуемая на намагничивание детали, пропорциональна величине намагниченности (М) и зависит от свойств материала:

$$
W 1=K 3 \times V,
$$

где КЗ - коэффициент, учитывающий электромагнитные свойства материала.

Для каждой стали существует определенная величина напряженности импульсного магнитного поля, а следовательно и величина магнитной энергии $W 1$, которая поглощается материалом в течение времени обработки $(t)$ и максимально улучшает его механические и технологические свойства. Между повышением стойкости детали и магнитной проницаемостью существует корреляционная зависимость.

Магнитострикционное упрочнение быстрорежущей стали, вызывающее улучшение физико-механических свойств материала, тесно связано с напряженностью наложенного на инструментальный материал магнитного поля.

Из рис. 2 следует, что с увеличением напряженности магнитного поля, в котором проводилась обработка инструмента, возрастало и значение твердости и теплостойкости стали Р6М5К5.

Импульсное магнитное поле, взаимодействуя с материалом детали, изменяет ее тепловые и электромагнитные свойства, улучшает структуру и эксплуатационные характеристики, что положено в основу технологии магнитного упрочнения.

Первопричиной улучшения эксплуатационных характеристик инструмента, подвергнутого магнитной обработке, является изменение свойств инструментального материала. Оно происходит за счет магнитострикционного упрочнения быстрорежущей стали, что вырождается в повышение ее теплостойкости.

При магнитной обработки детали вследствие неоднородной кристаллической структуры в ней возникают вихревые токи. Вихревые токи обуславливают магнитное поле и локальные микровихри, которые в свою очередь, нагревают участки вокруг кристаллитов напряженных блоков и неоднородностей структуры металла. В местах концентрации остаточных или усталостных напряжений, связанных с технологией производства, обработки или эксплуатации детали теплота, наведенная при МИО, вихревыми токами, частично уменьшает избыточную энергию составляющих кристаллитов и зерен структуры образца особенно в зоне контакта напряженных участков.

После обработки импульсным магнитным полем в инструментальном материале происходят изменения, как в кристаллической решетке матрицы, так и в карбидной фазе.

Обработка инструмента в постоянных и переменных магнитных полях может привести к повышению стойкости инструмента, не зависимо от его магнитного состояния. Это 
объясняется воздействием магнитного поля на структурное изменение состояния быстрорежущей стали. В этом случае происходит распад остаточного аустенита в поверхностном, вторично закаленном слое быстрорежущей стали.

Атермическое мартенситное превращение возникает в результате увеличения амплитуды колебаний кристаллической решетки аустенита, которые стремятся превратить ее в решетку мартенсита. Под воздействием импульсного магнитного поля возбуждение вызвано изменением направления спиновых моментов электронов, в том числе в ядрах дислокаций, что сопровождается появлением упругих напряжений магнитострикционной природы и активизацией дислокационных процессов.

Релаксационный процесс в условиях ускоренной диффузии протекает в инструментальном материале после воздействия поля при комнатной температуре и переводит систему дефектов структуры в квазиравновесное состояние, которое характеризуется новым распределением дефектных комплексов и пониженным уровнем внутренних напряжений.

Время выдержки инструмента в процессе магнитной обработки является важным элементом режима магнитной обработки. Для стали Р6М5 (рис. 3) достаточно времени воздействия магнитного поля в течение 60 сек., чтобы достичь наибольшего увеличения твердости материала.

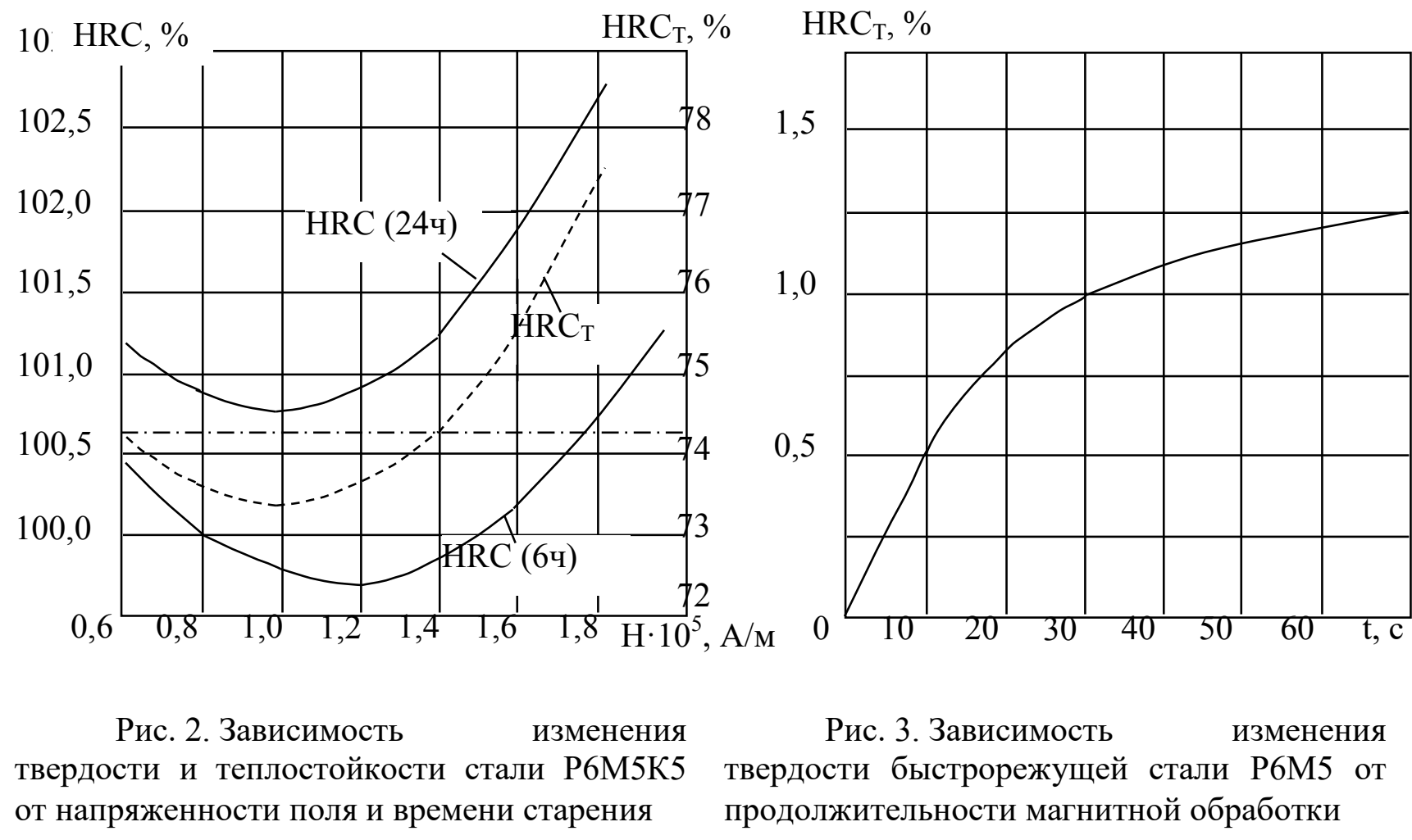

Относительно слабые магнитные поля не приводят к изменению значений твёрдости и теплостойкости (рис. 4). Установлено, что наибольшее повышение стойкости магнитнообработанного инструмента и наибольшее повышение значений твёрдости и теплостойкости получены при одних и тех же значениях рабочего поля $\left(H_{0}=1,2 \cdot 10^{5} \mathrm{~A} / \mathrm{M}\right)$.

Дальнейшее увеличение напряженности поля приводит к снижению твёрдости и теплостойкости и при $H=1,6 \cdot 10^{5} \mathrm{~A} / \mathrm{м}$ эти параметры практически не отличаются от твёрдости и теплостойкости образцов в исходном положении. 


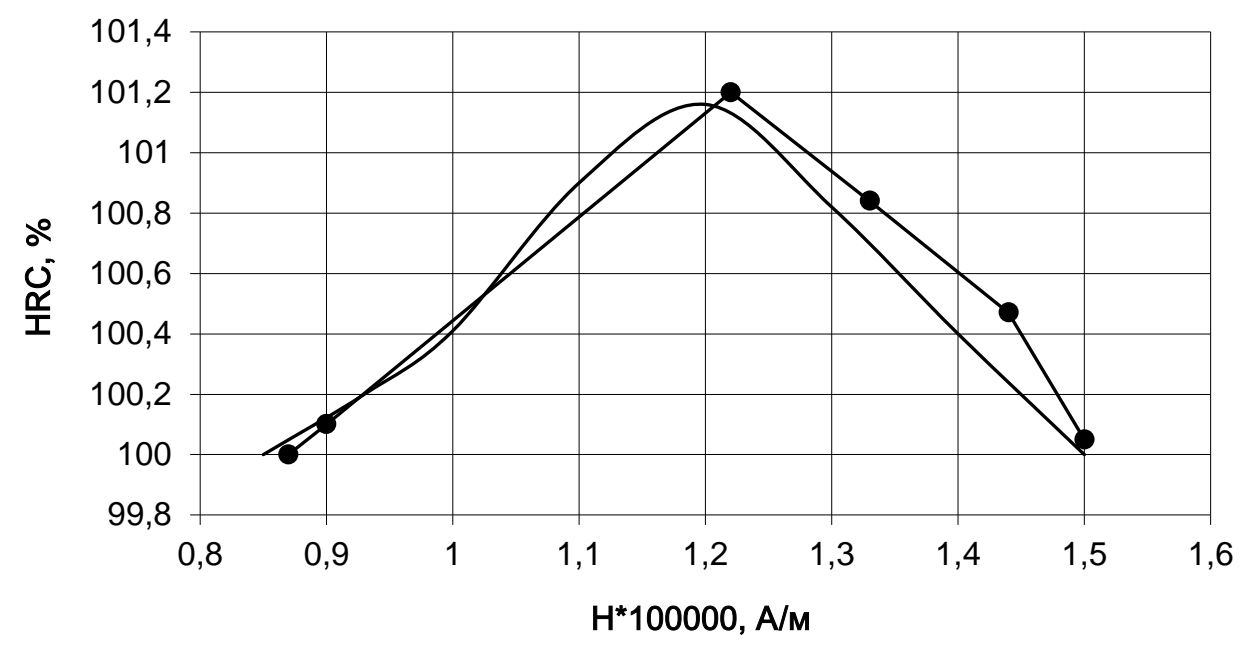

a

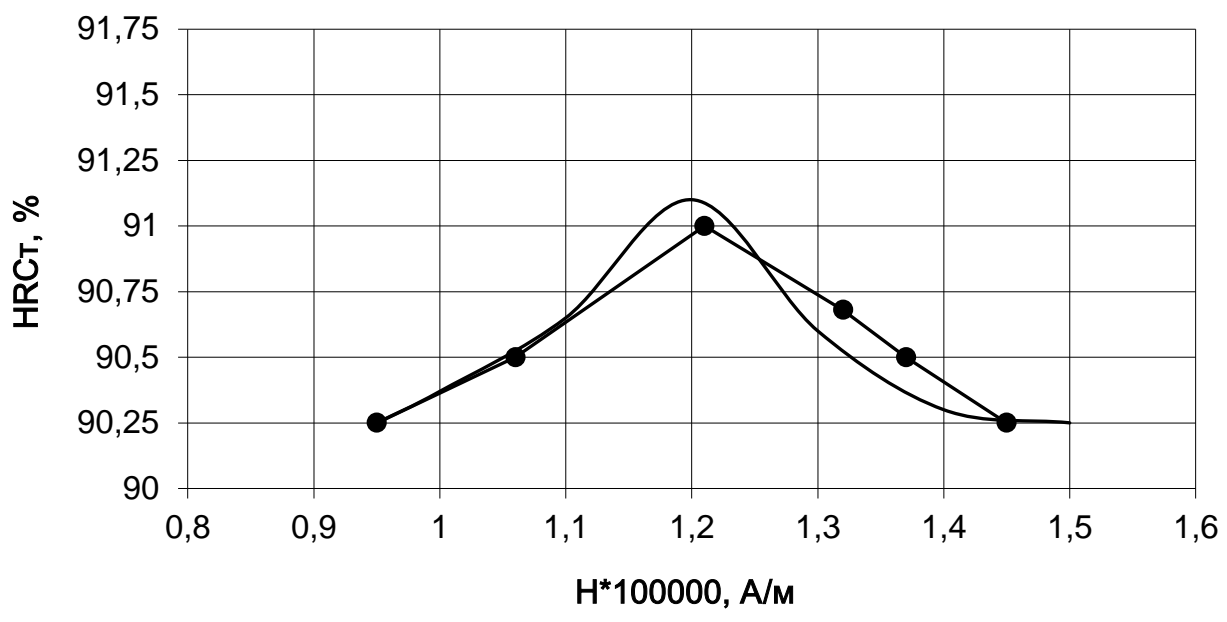

б

Рис. 4. Зависимость изменения твердости и теплостойкости стали Р6М5 от напряженности магнитного поля

Максимальное повышение твёрдости и теплостойкости быстрорежущей стали при напряженности поля $H_{0}=1,2 \cdot 10^{5} \mathrm{~A} / \mathrm{M}$ происходит за счёт магнитострикционного субструктурного упрочнения.

Процесс магнитнодисперсионного твердения протекает не мгновенно, а через некоторое время после операции магнитной обработки, чтобы стабилизировать новые свойства инструментальной стали.

Динамика старения изучалась на образцах из быстрорежущей стали Р6М5. Окончанием времени старения считалось такое время, по истечению которого прекращалось изменение твердости образцов.

Установлено, что рост твердости образцов из стали марки Р6М5 начинается после 6 часов после обработки и через 24 часа после этой операции достигает наибольших значений.

Одновременно с тепловыми процессами за счет импульсного магнитного поля в металле происходит полярная ориентация спинов электронов атомов, расположенных в области контакта кристаллитов и зерен сплавов, вследствие чего улучшаются механические свойства материала. 


\section{ВЫВОДЫ}

Проведенный анализ влияния параметров режима магнитной обработки на структурные изменения в инструменте из быстрорежущей стали позволяет сделать следующие выводы:

- в результате воздействия импульсного магнитного поля происходит изменение физико-механических свойств быстрорежущих сталей, возрастает холодная и горячая твёрдость и инструментальный материал становится более однородным по структуре;

- для устойчивого проявления эффекта магнитной обработки инструмента необходимо в каждом конкретном случае учитывать значение напряженности магнитного поля, время выдержки инструмента в рабочем индукторе и время старения инструмента после магнитной обработки;

- наибольшее повышение стойкости магнитнообработанного инструмента и наибольшее повышение значений твёрдости и теплостойкости получены при одних и тех же значениях рабочего поля;

- повышение стойкости инструмента происходит не за счет недостатков термической обработки, а за счет улучшения свойств инструментального материала и в первую очередь таких эксплуатационных свойств, как твердость и теплостойкость;

- импульсное магнитное поле, взаимодействуя с материалом детали, изменяет ее тепловые и электромагнитные свойства, улучшает структуру и эксплуатационные характеристики.

\section{СПИСОК ИСПОЛЬЗОВАННОЙ ЛИТЕРАТУРЫ}

1. Кинденко Н. И. Повышение надежности вольфрамосодержащего инструмента обработкой в импульсном магнитном поле. Надійність інструменту та оптимізаиія технологічних систем. Краматорськ: ДДМА, 2005. № 17. С. 113-118.

2. Володин В. Л., Зуев Л. Б., Володин Т. В., Гайдук В. В. Исследование влияния магнитно-импульсных поверхностных воздействий на эксплуатационные характеристики инструментальных сталей и инструмента. Известия высших учебных заведений. Черная металлургия. 2009. № 6. С. 61-65.

3. Кантович Л. И., Малыгин Б. В., Первов К. М. Повышение ресурса инструмента и деталей горных машин методом магнитной обработки. Горное оборудование и электромеханика. 2007. № 1. С. $13-16$.

\section{REFERENCES}

1. Kindenko N.I. Improving the reliability of a tungsten-containing tool by processing in a pulsed magnetic field. Tool reliability and optimization of technological systems. Kramatorsk: DSEA. 2005. 17, pp.113-118.

2. Volodin V.L., Zuev L.B., Volodin T.V., Gaiduk V.V. Investigation of the influence of magnetic-pulse surface effects on the performance characteristics of tool steels and tools. Ferrous metallurgy. 2009. 6, pp.61-65.

3. Kantovich L.I., Malygin B.V., Pervov K.M. Increasing the resource of tools and parts of mining machines by magnetic processing. Mining equipment and electromechanics. 2007. 1, pp. 13-16.

Кинденко Н. И. - канд. техн. наук, доц. ДГМА.

ДГМА - Донбасская государственная машиностроительная академия, г. Краматорск.

E-mail: okmm@dgma.donetsk.ua 